\title{
TWO SHARP OSTROWSKI-LIKE INEQUALITIES AND APPLICATIONS *
}

\author{
NENAD UJEVIĆ ${ }^{\dagger}$
}

\begin{abstract}
Two sharp inequalities are derived. The first of them is a sharp inequality which gives an error bound for a Gauss-Legendre quadrature rule. The second is a sharp inequality which gives an error bound for a Radau quadrature rule. These inequalities enlarge the applicability of the corresponding quadrature rules with respect to the obtained error bounds. Applications in numerical integration are also given.
\end{abstract}

1. Introduction. In recent years a number of authors have considered inequalities which give explicit error bounds for some known and some new quadrature formulas. For example, the Simpson's inequality (which gives an error bound for the wellknown Simpson's rule) is considered in [1], [4], [5], [7], [8] and [13]. Some Gaussian and Gaussian-like quadrature rules are considered in [14]. Inequalities of Ostrowski type are considered in [2], [5], [7] and [13].

In this paper we first derive a sharp inequality for absolutely continuous functions with derivatives which belong to $L_{2}(a, b)$. The sharpness is demonstrated by showing an equality for a particular absolutely continuous function. This inequality gives an error bound for a Gauss-Legendre quadrature rule.

Second, we derive a sharp inequality which gives an error bound for a Radau quadrature rule. It is obtained for the same class of functions as the above mentioned inequality. The sharpness is demonstrated by showing an equality for a particular absolutely continuous function, too.

The above mentioned results, which will be derived in this paper, enlarge applicability of the underlying quadrature rules. Namely, using the obtained estimates we can apply these rules to a larger class of functions than previous obtained results ensured. It is shown that the obtained inequalities can be applied in some cases where the above mentioned inequalities cannot be applied. Similar results, which enlarge the applicability of the trapezoidal rule and Simpson's rule, can be found in [3].

Finally, applications in numerical integration are given.

\section{Main results.}

LEMMA 1. Let

$$
f(t)=\left\{\begin{array}{ll}
f_{1}(t), & t \in\left[a, x_{0}\right] \\
f_{2}(t), & t \in\left(x_{0}, b\right]
\end{array},\right.
$$

where $x_{0} \in(a, b), f_{1} \in C^{1}\left(a, x_{0}\right), f_{2} \in C^{1}\left(x_{0}, b\right)$ and $f_{1}\left(x_{0}\right)=f_{2}\left(x_{0}\right)$ If

$$
\alpha_{1}=\sup _{t \in\left(a, x_{0}\right)}\left|f_{1}^{\prime}(t)\right|<\infty
$$

and

$$
\alpha_{2}=\sup _{t \in\left(x_{0}, b\right)}\left|f_{2}^{\prime}(t)\right|<\infty
$$

\footnotetext{
${ }^{*}$ Received March 27, 2003; accepted for publication November 6, 2003.

${ }^{\dagger}$ Department of Mathematics, University of Split, Teslina 12/III, 21000 Split, Croatia (ujevic@pmfst.hr).
} 
then $f$ is an absolutely continuous function.

The proof may be easily done utilizing elementary analysis. We omit the details.

REMARK 2. Let

$$
f(t)=\left\{\begin{array}{l}
f_{1}(t), \quad t \in\left[a, x_{1}\right] \\
f_{2}(t), \quad t \in\left(x_{1}, x_{2}\right) \\
f_{3}(t), \quad t \in\left[x_{2}, b\right]
\end{array}\right.
$$

where $a<x_{1}<x_{2}<b, f_{1} \in C^{1}\left(a, x_{1}\right), f_{2} \in C^{1}\left(x_{1}, x_{2}\right), f_{3} \in C^{1}\left(x_{2}, b\right)$ and $f_{1}\left(x_{1}\right)=$ $f_{2}\left(x_{1}\right), f_{2}\left(x_{2}\right)=f_{3}\left(x_{2}\right)$. If

$$
\begin{gathered}
\sup _{t \in\left(a, x_{1}\right)}\left|f_{1}^{\prime}(t)\right|<\infty, \\
\sup _{t \in\left(x_{1}, x_{2}\right)}\left|f_{2}^{\prime}(t)\right|<\infty, \\
\sup _{t \in\left(x_{2}, b\right)}\left|f_{3}^{\prime}(t)\right|<\infty
\end{gathered}
$$

then the above function $f$ is an absolutely continuous function.

We define the Chebyshev functional

$$
T(f, g)=\frac{1}{b-a} \int_{a}^{b} f(t) g(t) d t-\frac{1}{(b-a)^{2}} \int_{a}^{b} f(t) d t \int_{a}^{b} g(t) d t .
$$

Then

$$
T(f, f)=\frac{1}{b-a}\|f\|_{2}^{2}-\frac{1}{(b-a)^{2}}\left(\int_{a}^{b} f(t) d t\right)^{2}
$$

We also define

$$
\sigma(f)=(b-a) T(f, f)
$$

and

$$
S(f, g)=(b-a) T(f, g) .
$$

THEOREM 3. Let $f:[-1,1] \rightarrow R$ be an absolutely continuous function whose derivative $f^{\prime} \in L_{2}(-1,1)$ and $x_{1}=-\frac{\sqrt{3}}{3}, x_{2}=\frac{\sqrt{3}}{3}$. Then

$$
\left|f\left(x_{1}\right)+f\left(x_{2}\right)-\int_{-1}^{1} f(t) d t\right| \leq \sqrt{\frac{4-2 \sqrt{3}}{3}} \sigma\left(f^{\prime}\right)^{1 / 2},
$$

where $\sigma$ is defined by (4). Inequality (5) is sharp in the sense that the constant $\sqrt{\frac{4-2 \sqrt{3}}{3}}$ cannot be replaced by a smaller one. 
Proof. We define the function

$$
K(t)=\left\{\begin{array}{lr}
t+1, & t \in\left[-1, x_{1}\right] \\
t, & t \in\left(x_{1}, x_{2}\right) \\
t-1, & t \in\left[x_{2}, 1\right]
\end{array} .\right.
$$

Integrating by parts, we obtain

$$
\begin{aligned}
\int_{-1}^{1} K(t) f^{\prime}(t) d t & =\int_{-1}^{x_{1}}(t+1) f^{\prime}(t) d t+\int_{x_{1}}^{x_{2}} t f^{\prime}(t) d t+\int_{x_{2}}^{1}(t-1) f^{\prime}(t) d t \\
& =f\left(x_{1}\right)+f\left(x_{2}\right)-\int_{-1}^{1} f(t) d t .
\end{aligned}
$$

We also have

$$
\begin{aligned}
& \int_{-1}^{1} K(t) f^{\prime}(t) d t \\
= & \int_{-1}^{1}\left[K(t)-\frac{1}{2} \int_{-1}^{1} K(s) d s\right]\left[f^{\prime}(t)-\frac{1}{2} \int_{-1}^{1} f^{\prime}(s) d s\right] d t \\
= & 2 T\left(K, f^{\prime}\right)=S\left(K, f^{\prime}\right),
\end{aligned}
$$

since in this case $a=-1, b=1$, and

$$
\int_{-1}^{1} K(t) d t=0
$$

We now estimate

$$
\begin{aligned}
& S\left(K, f^{\prime}\right)^{2} \\
= & \left\{\int_{-1}^{1}\left[K(t)-\frac{1}{2} \int_{-1}^{1} K(s) d s\right]\left[f^{\prime}(t)-\frac{1}{2} \int_{-1}^{1} f^{\prime}(s) d s\right] d t\right\}^{2} \\
\leq & \int_{-1}^{1}\left[K(t)-\frac{1}{2} \int_{-1}^{1} K(s) d s\right]^{2} d t \int_{-1}^{1}\left[f^{\prime}(t)-\frac{1}{2} \int_{-1}^{1} f^{\prime}(s) d s\right]^{2} d t \\
= & \frac{4-2 \sqrt{3}}{3} S\left(f^{\prime}, f^{\prime}\right),
\end{aligned}
$$

since

$$
\int_{-1}^{1}\left[K(t)-\frac{1}{2} \int_{-1}^{1} K(s) d s\right]^{2} d t=\frac{4-2 \sqrt{3}}{3}
$$

From (7)-(11) we see that (5) holds. 
We have to prove that (5) is sharp. For that purpose, we define the function

$$
f(t)=\left\{\begin{array}{lr}
\frac{1}{2}(t+1)^{2}, & t \in\left[-1, x_{1}\right] \\
\frac{1}{2} t^{2}+x_{1}+\frac{1}{2}, & t \in\left(x_{1}, x_{2}\right) \\
\frac{1}{2}(t-1)^{2}, & t \in\left[x_{2}, 1\right]
\end{array} .\right.
$$

The function $f$, given by (12), is an absolutely continuous function (see Remark 2).

We now calculate

$$
\begin{aligned}
& \int_{-1}^{1} f(t) d t \\
= & \int_{-1}^{x_{1}} \frac{1}{2}(t+1)^{2} d t+\int_{x_{1}}^{x_{2}}\left[\frac{1}{2} t^{2}+x_{1}+\frac{1}{2}\right] d t+\int_{x_{2}}^{1} \frac{1}{2}(t-1)^{2} d t=0
\end{aligned}
$$

and

$$
f\left(x_{1}\right)+f\left(x_{2}\right)=\frac{4-2 \sqrt{3}}{3} .
$$

From (13) and (14) we find that the left-hand side of (5) is equal to

$$
\text { L.H.S. }(5)=\frac{4-2 \sqrt{3}}{3} .
$$

On the other hand, for the right-hand side of (5) we find

$$
\begin{aligned}
& R . H . S .(5) \\
= & \int_{-1}^{1} f^{\prime}(t)^{2} d t=\int_{-1}^{1} K(t)^{2} d t=\frac{4-2 \sqrt{3}}{3} .
\end{aligned}
$$

From (15) and (16) we see that L.H.S.(5) = R.H.S.(5), if the function $f$ is given by (12). This completes the proof.

TheOREm 4. Let $f:[-1,1] \rightarrow R$ be an absolutely continuous function whose derivative $f^{\prime} \in L_{2}(-1,1)$ and $x_{1}=-1, x_{2}=\frac{1}{3}$. Then

$$
\left|\frac{1}{2} f\left(x_{1}\right)+\frac{3}{2} f\left(x_{2}\right)-\int_{-1}^{1} f(t) d t\right| \leq \frac{1}{\sqrt{3}} \sigma\left(f^{\prime}\right)^{1 / 2}
$$

where $\sigma$ is defined by (4). Inequality (17) is sharp in the sense that the constant $1 / \sqrt{3}$ cannot be replaced by a smaller one.

Proof. We define the function

$$
K(t)=\left\{\begin{array}{lr}
t+\frac{1}{2}, & t \in\left[-1, x_{2}\right] \\
t-1, & t \in\left[x_{2}, 1\right]
\end{array} .\right.
$$


Integrating by parts, we obtain

$$
\begin{aligned}
\int_{-1}^{1} K(t) f^{\prime}(t) d t & =\int_{-1}^{x_{2}}\left(t+\frac{1}{2}\right) f^{\prime}(t) d t+\int_{x_{2}}^{1}(t-1) f^{\prime}(t) d t \\
& =\frac{1}{2} f\left(x_{1}\right)+\frac{3}{2} f\left(x_{2}\right)-\int_{-1}^{1} f(t) d t .
\end{aligned}
$$

We also have

$$
\begin{aligned}
& \int_{-1}^{1} K(t) f^{\prime}(t) d t \\
= & \int_{-1}^{1}\left[K(t)-\frac{1}{2} \int_{-1}^{1} K(s) d s\right]\left[f^{\prime}(t)-\frac{1}{2} \int_{-1}^{1} f^{\prime}(s) d s\right] d t \\
= & 2 T\left(K, f^{\prime}\right)=S\left(K, f^{\prime}\right),
\end{aligned}
$$

since in this case $a=-1, b=1$ and

$$
\int_{-1}^{1} K(t) d t=0 .
$$

We now estimate

$$
\begin{aligned}
& S\left(K, f^{\prime}\right)^{2} \\
= & \left.\int_{-1}^{1}\left[K(t)-\frac{1}{2} \int_{-1}^{1} K(s) d s\right]\left[f^{\prime}(t)-\frac{1}{2} \int_{-1}^{1} f^{\prime}(s) d s\right] d t\right\}^{2} \\
\leq & \int_{-1}^{1}\left[K(t)-\frac{1}{2} \int_{-1}^{1} K(s) d s\right]^{2} d t \int_{-1}^{1}\left[f^{\prime}(t)-\frac{1}{2} \int_{-1}^{1} f^{\prime}(s) d s\right]^{2} d t \\
= & \frac{1}{3} S\left(f^{\prime}, f^{\prime}\right),
\end{aligned}
$$

since

$$
\int_{-1}^{1}\left[K(t)-\frac{1}{2} \int_{-1}^{1} K(s) d s\right]^{2} d t=\frac{1}{3} .
$$

From (19)-(23) we see that (17) holds.

We have to prove that (17) is sharp. For that purpose, we define the function

$$
f(t)=\left\{\begin{array}{lr}
\frac{1}{2}\left(t+\frac{1}{2}\right)^{2}, & t \in\left[-1, x_{2}\right] \\
\frac{1}{2}(t-1)^{2}+\frac{1}{8}, & t \in\left[x_{2}, 1\right]
\end{array} .\right.
$$

The function $f$, given by (24), is an absolutely continuous function (see Lemma 1 ). 
We now calculate

$$
\begin{aligned}
& \int_{-1}^{1} f(t) d t \\
= & \int_{-1}^{\frac{1}{3}} \frac{1}{2}\left(t+\frac{1}{2}\right)^{2} d t+\int_{\frac{1}{3}}^{1}\left(\frac{1}{2}(t-1)^{2}+\frac{1}{8}\right) d t=\frac{1}{4}
\end{aligned}
$$

and

$$
\frac{1}{2} f\left(x_{1}\right)+\frac{3}{2} f\left(x_{2}\right)=\frac{7}{12} .
$$

From (25) and (26) we find that the left-hand side of (17) is equal to

$$
\text { L.H.S. }(17)=\frac{1}{3} \text {. }
$$

On the other hand, for the right-hand side of (17) we find

$$
\begin{aligned}
& \text { R.H.S.(17) } \\
= & \int_{-1}^{1} f^{\prime}(t)^{2} d t=\int_{-1}^{1} K(t)^{2} d t=\frac{1}{3} .
\end{aligned}
$$

From (27) and (28) we see that L.H.S.(17) = R.H.S.(17), if the function $f$ is given by (24). This completes the proof.

The estimations (5) and (17) are not the best possible. We have better estimations of errors. For example, in [15] we can find the following results. Let $I$ be an open interval and $[-1,1] \subset I$. If $f: I \rightarrow R$ is a differentiable function and there exist real numbers $\gamma, \Gamma$ such that $\gamma \leq f^{\prime}(t) \leq \Gamma, t \in[-1,1]$ then we have

$$
\left|f\left(x_{1}\right)+f\left(x_{2}\right)-\int_{-1}^{1} f(t) d t\right| \leq \frac{\Gamma-\gamma}{6}(5-2 \sqrt{3})
$$

where $x_{1}=-\frac{\sqrt{3}}{3}$ and $x_{2}=\frac{\sqrt{3}}{3}$ and

$$
\left|\frac{1}{2} f\left(x_{1}\right)+\frac{3}{2} f\left(x_{2}\right)-\int_{-1}^{1} f(t) d t\right| \leq \frac{25}{72}(\Gamma-\gamma),
$$

where $x_{1}=-1$ and $x_{2}=\frac{1}{3}$.

It is obvious that (29) and (30) are better than (5) and (17), respectively. However, we also have the following example.

EXAMPLE 5. Let us consider the integral $\int_{0}^{1} \sqrt[3]{\sin t^{2}} d t$. We have

$$
f(t)=\sqrt[3]{\sin t^{2}} \text { and } f^{\prime}(t)=\frac{2 t \cos t^{2}}{3 \sqrt[3]{\sin ^{2} t^{2}}}
$$


such that $f^{\prime}(t) \rightarrow \infty, \quad t \rightarrow 0$ and we cannot apply the estimates (29) and (30). On the other hand, we have

$$
\int_{0}^{1}\left[f^{\prime}(t)\right]^{2} d t \leq \frac{4}{9} \max _{t \in[0,1]} \frac{t^{2} \cos t^{2}}{\sin t^{2}} \int_{0}^{1} \frac{d t}{\sqrt[3]{\sin t^{2}}} \leq \frac{16}{9},
$$

i.e. $\left\|f^{\prime}\right\|_{2} \leq \frac{4}{3}$ and we can apply the estimates (5) and (17).

REMARK 6. Hence, although the estimates (29) and (30) are better than the estimates (5) and (17) the last mentioned estimates have their field of application. Furthermore, they are sharp and they are proved for a larger class of functions.

3. Composite quadrature rules. With the aid of the quadrature formulas given in Theorems 3 and 4, which will be called canonical, we can form the composite quadrature formulas on an arbitrary interval $[a, b]$. To this end, divide the interval $[a, b]$ into $n$ equal subintervals $\left[x_{k}, x_{k+1}\right], x_{k}=a+k(b-a) / n, k=0,1,2, \ldots, n-1$ and $x_{n}=b$. On each subinterval $\left[x_{k}, x_{k+1}\right]$ we specify two nodes

$$
x_{k_{j}}=\frac{x_{k}+x_{k+1}}{2}+y_{j} \frac{b-a}{2 n}, j=1,2,
$$

where $y_{j}$ are the nodes of the corresponding canonical formulas. By virtue of this, we get the quadrature formula

$$
\int_{x_{k}}^{x_{k+1}} f(t) d t=\frac{b-a}{n} \sum_{j=1}^{2} w_{j} f\left(x_{k_{j}}\right)+R_{k}(f),
$$

where $w_{j}$ are the weights of the corresponding canonical formulas. Summing the relation (32) over $k$ from 0 to $n-1$, we obtain the composite quadrature formula

$$
\int_{a}^{b} f(t) d t=\frac{b-a}{n} \sum_{j=1}^{2} w_{j} \sum_{k=0}^{n-1} f\left(x_{k_{j}}\right)+R(f) .
$$

We define

$$
\sigma_{n}(f)=\sum_{k=0}^{n-1} \sqrt{\frac{b-a}{n}\left\|f^{\prime}\right\|_{2}^{2}-\left[f\left(x_{k+1}\right)-f\left(x_{k}\right)\right]^{2}}
$$

and

$$
\omega_{n}(f)=\left[(b-a)\left\|f^{\prime}\right\|_{2}^{2}-\frac{1}{n}\left(f\left(x_{n}\right)-f\left(x_{0}\right)\right)^{2}\right]^{1 / 2}
$$

THEOREM 7. Under the notations defined above let $f:[a, b] \rightarrow R$ be an absolutely continuous function such that $f^{\prime} \in L_{2}(a, b)$. Then

$$
\begin{aligned}
\left|\int_{a}^{b} f(t) d t-\frac{h}{2} \sum_{k=0}^{n-1}\left[f\left(x_{k 1}\right)+f\left(x_{k 2}\right)\right]\right| & \leq \frac{b-a}{2 \sqrt{3} n} \sqrt{2-\sqrt{3}} \sigma_{n}(f) \\
& \leq \frac{b-a}{2 \sqrt{3 n}} \sqrt{2-\sqrt{3}} \omega_{n}(f),
\end{aligned}
$$


where

$$
x_{k 1}=\frac{x_{k}+x_{k+1}}{2}-\frac{\sqrt{3}}{6} h, \quad x_{k 2}=\frac{x_{k}+x_{k+1}}{2}+\frac{\sqrt{3}}{6} h
$$

and $h=(b-a) / n$.

Proof. From (31), (32) and Theorem 3 we have

$$
\int_{x_{k}}^{x_{k+1}} f(t) d t=\frac{h}{2}\left[f\left(x_{k 1}\right)+f\left(x_{k 2}\right)\right]+R_{k}(f),
$$

where

$$
\left|R_{k}(f)\right| \leq \frac{h^{3 / 2}}{2 \sqrt{3}} \sqrt{2-\sqrt{3}} \sigma\left(f^{\prime}\right)^{1 / 2} .
$$

If we now sum (37) over $k$ from 0 to $n-1$ then we get

$$
\int_{a}^{b} f(t) d t=\frac{h}{2} \sum_{k=0}^{n-1}\left[f\left(x_{k 1}\right)+f\left(x_{k 2}\right)\right]+\sum_{k=0}^{n-1} R_{k}(f) .
$$

From (39) and (38) we easily find that the first inequality in (36) holds.

Using the Cauchy inequality we get

$$
\begin{aligned}
\sigma_{n}(f) & =\sum_{k=0}^{n-1} \sqrt{\frac{b-a}{n}-\left[f\left(x_{k+1}\right)-f\left(x_{k}\right)\right]^{2}} \\
& \leq \sqrt{n}\left[(b-a)\left\|f^{\prime}\right\|_{2}^{2}-\sum_{k=0}^{n-1}\left[f\left(x_{k+1}\right)-f\left(x_{k}\right)\right]^{2}\right]^{1 / 2} \\
& \leq \sqrt{n} \sqrt{(b-a)\left\|f^{\prime}\right\|_{2}^{2}-\frac{1}{n}\left(f\left(x_{n}\right)-f\left(x_{0}\right)\right)^{2}}
\end{aligned}
$$

since

$$
\sum_{k=0}^{n-1}\left[f\left(x_{k+1}\right)-f\left(x_{k}\right)\right]=f\left(x_{n}\right)-f\left(x_{0}\right) .
$$

This proves the second inequality in (36).

THEOREM 8. Under the assumptions of Theorem 7 we have

$$
\begin{aligned}
\left|\int_{a}^{b} f(t) d t-h \sum_{k=0}^{N-1}\left[\frac{1}{4} f\left(x_{k 1}\right)+\frac{3}{4} f\left(x_{k 2}\right)\right]\right| & \leq \frac{b-a}{2 \sqrt{6} n} \sigma_{n}(f) \\
& \leq \frac{b-a}{2 \sqrt{6 n}} \omega_{n}(f),
\end{aligned}
$$

where

$$
x_{k 1}=x_{k}, \quad x_{k 2}=\frac{x_{k}+x_{k+1}}{2}-\frac{h}{6} .
$$


Proof. From (31), (32) and Theorem 4 we have

$$
\int_{x_{k}}^{x_{k+1}} f(t) d t=h\left[\frac{1}{4} f\left(x_{k 1}\right)+\frac{3}{4} f\left(x_{k 2}\right)\right]+R_{k}(f),
$$

where

$$
\left|R_{k}(f)\right| \leq \frac{h^{3 / 2}}{2 \sqrt{6}} \sigma\left(f^{\prime}\right)^{1 / 2} .
$$

If we now sum (41) over $k$ from 0 to $n-1$ then we get

$$
\int_{a}^{b} f(t) d t=h \sum_{k=0}^{n-1}\left[\frac{1}{4} f\left(x_{k 0}\right)+\frac{3}{4} f\left(x_{k 1}\right)\right]+\sum_{k=0}^{n-1} R_{k}(f) .
$$

From (43) and (42) we easily find that the first inequality in (40) holds. A proof of the second inequality is similar to the prof of second inequality in Theorem 7 .

REMARK 9. The second inequalities in (36) and (40) are coarser than the first inequalities. They may be used to predict the number of steps needed in the compound rule for a given accuracy of the approximations. Of course, we shall use the first inequalities in (36) and (40) to obtain the error bounds. Note also that in this last case we use the same values $f\left(x_{i}\right)$ to calculate the approximations of the integral $\int_{a}^{b} f(t) d t$ and to obtain the error bounds and recall that function evaluations are generally considered the computationally most expensive part of quadrature algorithms.

\section{REFERENCES}

[1] P. Cerone, Three points rules in numerical integration, Nonlinear Anal.-Theory Methods Appl., 47:4 (2001), pp. 2341-2352.

[2] X. L. Cheng, Improvement of some Ostrowski-Grüss type inequalities, Comput. Math. Appl., 42 (2001), pp. 109-114.

[3] D. Cruz-Uribe And C. J. Neugebauer, Sharp error bounds for the trapezoidal rule and Simpson's rule, J. Inequal. Pure Appl. Math., 3(4), Article 49, (2002), pp. 1-22.

[4] S. S. Dragomir, R. P. Agarwal and P. Cerone, On Simpson's inequality and applications, J. Inequal. Appl., 5 (2000), pp. 533-579.

[5] S. S. Dragomir, P. Cerone and J. Roumeliotis, A new generalization of Ostrowski's integral inequality for mappings whose derivatives are bounded and applications in numerical integration and for special means, Appl. Math. Lett., 13 (2000), pp. 19-25.

[6] S. S. DRAGOMIR AND S. WANG, An inequality of Ostrowski-Grüss type and its applications to the estimation of error bounds for some special means and for some numerical quadrature rules, Comput. Math. Appl., 33 (1997), pp. 16-20.

[7] S. S. Dragomir, J. Pečarić and S. Wang, The unified treatment of trapezoid, Simpson and Ostrowski type inequalities for monotonic mappings and applications, Math. Comput. Modelling, 31 (2000), pp. 61-70.

[8] I. Fedotov and S. S. Dragomir, An inequality of Ostrowski type and its applications for Simpson's rule and special means, Math. Inequal. Appl., 2:4 (1999), pp. 491-499.

[9] A. Ghizzetti and A. Ossicini, Quadrature formulae, Birkhäuser Verlag, Basel/Stuttgart, 1970.

[10] M. MatiĆ, J. PEČARIĆ AND N. UJEvić, Improvement and further generalization of some inequalities of Ostrowski-Grüss type, Comput. Math. Appl., 39 (2000), pp. 161-175.

[11] D. S. Mitrinović, J. PeČArić AND A. M. Fink, Inequalities involving functions and their integrals and derivatives, Kluwer Acad. Publ., Dordrecht, 1991.

[12] I. P. Natanson, Theory of functions of real variable, Nauka, Moscow, 1974. 
[13] C. E. M. Pearce, J. PeČarić, N. Ujević and S. Varošanec, Generalizations of some inequalities of Ostrowski-Grüss type, Math. Inequal. Appl., 3:1 (2000), pp. 25-34.

[14] N. Ujević, Inequalities of Ostrowski-Grüss type and applications, Appl. Math., 29:4 (2002), pp. $465-479$.

[15] N. UJEvić, New bounds for the first inequality of Ostrowski-Grüss type and applications, Comput. Math. Appl., 46 (2003), pp. 421-427. 